\title{
17 Preserving autonomy and quality of life of the elderly
}

\section{The contribution of French gerontopoles}

\author{
Nathalie Barth, Clara Pizzolo, Solène Dorier, \\ Régis Gonthier and Thomas Célarier
}

This chapter is based on a double qualitative methodology since it consists of both a review of the scientific literature and institutional texts as well as interviews with key players of the French gerontopoles and local structures working in the field of ageing of the population. Interviewing key players of gerontopoles allowed us to obtain a general view of these structures, while the local structures gave us a vision that is more specific to each territory and more critical of these new organizations. The semi-structured interviews, which were conducted with an interview guide based on the literature review, clearly identified theoretical approaches and feedback from the field. They were transcribed and analyzed in their entirety.

The review of the literature allowed us to identify the issue of the ageing of the population as well as the various policy areas developed in France to respond to this demographic transition. We were therefore interested in the 2015 law "adapting the society to ageing", which led to the creation of the gerontopoles.

The purpose of this chapter is to present and understand the functioning of French gerontopoles, their missions and their organization to identify representations related to these structures.

\section{Introduction}

Effectively managing the ageing of our population, providing home care services for people made vulnerable by ageing and improving the quality of life of our elderly is a major public health challenge. The spectacular increase in life expectancy seen lately has led to a growing number of people reaching very old age (Champio et al., 2018). By 2050, ${ }^{1}$ the number of dependent elderly will have doubled according to the worst case estimations of the Libault Report (2019), and with this looming disaster, doubts are raised concerning institutional capacity to handle the demand, as well as families' ability to afford care. Building awareness of this evolution among our society's agents proves to be essential if we are to help make people conscious of this demographic transition and offer our elderly a better quality of life. Among the French, life expectancy is growing, while the age at which health deteriorates is remaining the same, only slightly increasing (INSEE, 2019); De Lapasse, 2018). The care provided for dependent elderly in institutions (nursing homes, sheltered accommodation) is rarely preferred by the elderly, who most often express desires to stay at home, within their social community and cultural surroundings. The choice to remain at home is initially left to the person concerned, ${ }^{2}$ yet is also influenced by factors governed by politics. As early as 1962, for example, the Laroque Commission Report revealed growing poverty among the elderly and identified "home care" as a factor that 


\section{N. Barth et al.}

could encourage and bolster a "third life stage of active, independent, and participatory living" (translation; Grand, 2016). Public healthcare policies (French law relating to social and medical-social institutions [1975]; rapport vieillir demain [ageing tomorrow] [1980]; Defferre Law [1982]; Allocation Personnalisé d'Autonomie [the French autonomous living benefit scheme] [2001] ...) progressively took the lead in ageing issues so as to improve how the elderly are treated and help insure healthier ageing at home. With the arrival of the 1980 s, there came recognition of unofficial care, the role of family and friend carers, and a will to support them. It was not until 2015 that the loi d'adaptation de la société au vieillissement (French Act on adapting society to an ageing population) (ASV) was made public, instigating a number of care services to be implemented, as designed to anticipate loss of autonomy, adapt society to ageing and accompany those suffering from loss of autonomy. This Act aimed "to enable all to benefit from the best possible social, economic, and healthcare conditions, for as long as possible, as life expectancy increases" (translation; ASV Act, 2015).

This demographic evolution was thus accompanied by economic, societal and scientific transitions requiring the participation of different regional bodies working in the field of

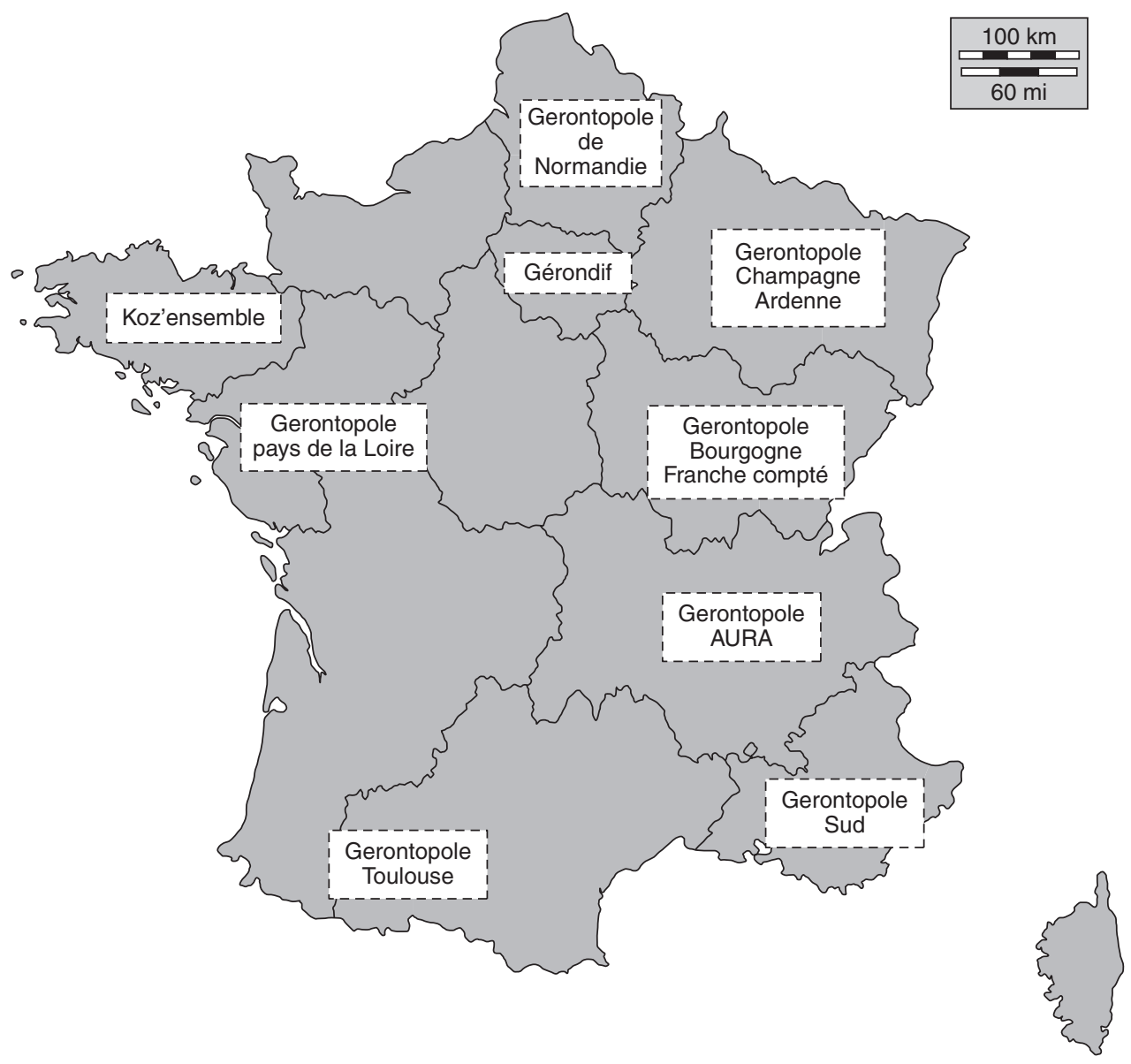

Figure 17.1 The gerontopoles of France. 
the elderly. The creation in France of gerontology-dedicated clusters, called "gerontopoles", ${ }^{3}$ was in order to respond to this need, "to develop all necessary services allowing to 'avoid the avoidable' in ageing and implement services to treat frailty and maintain elderly autonomy: early detection and management of frailty in the elderly/prevention of age-related disease and loss of autonomy" (Gonthier, Achour and Geffroy, 2015, translation).

Numbering nine centers in total in $2019,{ }^{4}$ these gerontopoles are designed to facilitate sharing of experience, research and innovation relating to ageing, while reducing social and territorial healthcare inequalities. Their mission is

to bring together and galvanize action on ageing among professionals working in research, healthcare (hospitals, city institutions, medical-social centers ...), training, and business. They seek to facilitate the transfer of research and technological development ("silver economy") to age-related healthcare, medical-social management, and services.

(translation; ASV Act, 2015)

The gerontopoles thus have a dual purpose: (1) to improve the quality of life of the elderly; (2) act as an information and excellence pipeline for all regional professionals working with this population.

While the French gerontopoles all aim to provide solutions to this issue of the current demographic evolution, notably by implementing preventative, educational and promotional actions for healthy ageing, great disparities are nonetheless observed in terms of their internal organization and development. The French government has had no hand in choosing finance sources or controlling specific operations. As a result, each French gerontopole operates differently, with varying scopes and organizational structures. This leads to the emergence of location-specific particularities: some gerontopoles are more focused on medical approaches, others on the silver economy and yet others on social matters.

This chapter aims to identify the strategic orientations of French gerontopoles considering local specificities, along with public healthcare policies. We have asked the following questions: how can a gerontopole best benefit French society? By reducing social and local healthcare inequalities? By improving the quality of life of the elderly and reducing healthcare costs through improvement in service quality? Finally, to what extent are these gerontology clusters innovative and able to be activated for research?

\section{Methodology}

With the aim of being as representative as possible of the missions, role and place of French gerontopoles, we opted to combine an analysis of the scientific literature and institutional texts with a qualitative analysis of the key players of these gerontopoles. We conducted 12 semi-directive interviews over four months (2019) with seven representatives of six different French gerontopoles, ${ }^{5}$ as well as regional-local professionals (five) ${ }^{6}$ By focusing on the AURA gerontopole's activity, we were able to investigate the local system's dynamics, as well as the existing collaborations/partnerships among all different players. The interviews lasted from 40 to 60 minutes, conducted face to face (seven) or by telephone (five), and were then fully transcribed each time. The subjects discussed were the presentation of the structure (organization, financing, concrete actions), level of cooperation and coordination, and place of the gerontopole within the local ecosystem. Our interview 


\section{N. Barth et al.}

analysis enabled us to identify the specificities of each studied gerontopole, the actions they were all committed to, and the local dynamics of each in terms of services promoting healthy ageing and elderly health, both on a social and research level.

\section{Results}

In order to improve the quality of life of our most elderly, the French gerontopoles were designed as part of a societal effort in the midst of a great demographic change, requiring a great number of different professionals to work together (hospital employees, human and social science researchers, professionals working in gerontology, communities and users, etc.), as well as to galvanize research and teaching that helps advance understanding of ageing and anticipate the related needs. What we were to find out was that despite having common goals, each studied gerontopole took a different stance vis-à-vis their social environment and in terms of the local particularities and dynamics.

\section{Creating the gerontopoles: galvanizing social action in the midst of demographic evolution}

In our Western societies, ageing is accepted as long as retired life can be led with a minimum of autonomy while links with society can be maintained. In France today, however, most frail elderly have been found to suffer from increased years spent incapacitated, along with severe isolation. With ageing necessarily comes frailty and chronic diseases, causing functional decline. The ability to live autonomously is reduced, and, little by little, dependent living becomes inevitable. As underlined by Gonthier, Achour and Geffroy (2015), developing living options near services and city-centers, while adapting public and private spaces to the needs of the elderly, could also contribute to helping them keep interacting with society while also benefitting from adapted and safe living conditions. Of all the isolated elderly, only 56 percent live in a town with over 100,000 inhabitants (Fondation de France, 2016). We need to find new solutions or alternatives in terms of living conditions, even though the elderly concerned are themselves resistant to change. Taking inspiration from the hotline-based direct-admissions service currently being tested in the geriatric wards of several French regions, we should also perhaps rethink how the elderly are managed when attending hospitals. In 2017, two out of five people aged 80 years or over were hospitalized, with the majority involving emergency care. Yet, there is no longer any doubt about the negative consequences of going through emergency care: malnutrition and weight loss, depression, disorientation and loss of autonomy, nosocomial infection transmission, sensory loss and confusion, risk of immobilization and so on. Being transferred from GP clinics to hospitals or ambulance transfers have proven to be traumatizing and should be anticipated by local professionals in order to improve how the elderly are taken care of when losing autonomy or approaching end of life.

These issues are of extreme relevance for the French National Solidarity Fund for Autonomy (Caisse Nationale de Solidarité pour l'Autonomie, CNSA); preventing loss of autonomy, promoting healthy active lifestyles (balanced diet, physical activity, stress management, anti-smoking measures ...), and early detection of at-risk populations are all essential public health matters that require mobilizing many healthcare professionals. As clusters designed to preserve elderly autonomy, the gerontopoles are just one part of a new raft of political actions being implemented: transforming healthcare services to better adapt to at-home users, simplifying healthcare pathways for those suffering from several chronic 
diseases and in situations complicated by isolation or autonomy loss, multiplying local services on the ground (keeping nearby shops open, adapting individual accommodation, ensuring availability of public transport and so on). The main goal is to help people age in a healthy way and encourage elderly citizens to stay active within society.

\section{Gerontopoles: encouraging collaboration and cooperation between all key players}

The quest for efficacy involves developing partner networks while also encouraging a collective effort for prevention among all professionals involved in gerontology, from family and friend carers to retirement community workers (volunteers), complementary social protection organizations, in-home nurses, healthcare professionals and community associations, and also businesses and start-ups invested in combatting ageing issues. Nevertheless, achieving good cooperation and collaboration among these different, widely contrasting groups is not an easy task and requires effective interaction and even, at times, negotiation. The quotes, below, are from interviews with representatives of gerontopoles.

These professionals are sometimes different, have never met each other, and evolve in worlds that have never overlapped.... We do manage to overcome this using communication techniques.

(translation; PGI, Director, gerontopole 2015)

In "healthy ageing" actions, there are so many different participants, and it is imperative they work

(administrative Koz'series, age of the gerontopole 2015)

The institutions remain isolated from each other due to the great diversity in their competences and expertise, the multiple and varying types of actions they perform, as well as the inherent issues in how the French healthcare system is structured in separate silos. Reports have also revealed the presence of other obstacles, such as project financing or time schedules that differ from institution to institution, as well as difficulties doing collaborative work with the highly diverse professionals working in this field.

The finance factor is a major obstacle. For me, the greatest hurdle is financing projects and the necessary time, yes time, too.... Some can bring in financing, others are more in research; depending on their legal status, they can be leader, contributor, financer, or other.

(Pays de la Loire gerontopole, CEO, gerontopole 2010)

It's about time and scheduling, especially when it comes to the silver economy, where, obviously, there are of course economic agents working off very short deadlines while institutional bodies, of support, are looking at longer time scales.

(PGI, Director, senior manager of gerontopole 2015).

So this means that while it's true that each professional is strong in his field, what we find the most challenging is working in what you could call a transdisciplinary way. That is what is very complicated, actually; working in gerontology really requires teamwork, meaning medicine, psychology, sociology, economy, and even politics working together.

(AURA Gerontopole, Medical Vice-President, gerontopole 2015). 
Still, all the gerontopoles are in agreement that collaboration on common goals is both necessary and demanded. Collaborative working also helps provide a better, more tailored response to needs; it means being able to surround yourself with new competences and knowledge, and uniting efforts for financing and projects.

I believe that it is by taking a wider view, involving all different professionals around the table, that we can progress... If everyone works alone in isolation, we can only partially respond to needs ... these agents have a great need to share knowledge with each other, and these institutions offer no space for just such sharing on population ageing, they have neither the means nor the expertise to make advances in the fiel.

(administrative Koz'series, age of gerontopole 2015)

We have professionals who really complement each other; however, we realize that what is so difficult is the transdisciplinary approach. Obviously, it works well if it is well designed from the start, with a solid structure where everyone knows exactly why they are there, what they will be able to get out of it.... It's quite a win-win situation, and after the project, you adjust, you adapt; it's never a straight line to the top.

(AURA gerontopole, vice medical director, gerontopole 2015)

Collaboration works most effectively when there are shared interests. The gerontopoles evoke real diversity and represent the value of a hub of expertise and knowledge. As for the institutions, they add value to all actions on the ground and local projects working to improve people's well-being, while businesses benefit from these areas that are ideal for experimentation, accelerating their projects (use surveys, for example). What motivates and benefits some can be different from others, though the goal is always the same: to improve the quality of life of our elderly.

The gerontopole will be the representation of what the local professionals need, that's why it's a truly collaborative product enriched by our annual action plan.... We take our lead from the needs of the professionals involved, on whichever subjects they particularly want to develop, and we are above all highly pragmatic; we chose this associative mode in order to be more agile, as reactive as possible. Our real winning asset is when we are able to offer flexibility to our partners.

(Director of the Gérond'if île de France gerontopole, gerontopole 2014)

Whatever their profession, be they medico-social professionals, economists or other, they all come for the expertise of our technical team, that's for sure! Then the facilitation and acceleration of their projects is very clear ... and some even see it as a longterm partnership, strategically so for some when they need to show financers or deciders that they are truly part of a collaborative dynamic.

(PGI, Director, age of gerontopole 2015)

We collaborate when we have a shared goal, nobody is naive enough to think otherwise. It enables us to have intelligent exchange, enriched collaborations, it's essential to fully understand the specificities of each player.

(PGI, Director, age of gerontopole 2015) 
Bringing together different professionals on the same projects and encouraging collaborative and cooperative work proves to be a goal for which the gerontopoles are particularly adept. Faced with the diversity of those working in the ageing field and the great number of services out there, coordination is essential for developing new healthy ageing policies that are adapted to the population's needs. The gerontopoles thus act as mediators for preventative and healthy ageing actions and as central components to bringing all the different players together.

There are so many different professionals, procedures, and diverse pathways, if we are to succeed in creating a healthy ageing policy, I believe we really have to work together, the field of ageing is so vast: from social to medical, involving carers, treatments ... I share the belief that we (the gerontopole) exist today because there was a void that needed filling, we identified the needs that required all of us to fulfil, not alone but together.

(Koz'ensemble Manager, gerontopole 2015)

We are here to mediate, as third-party agents on the front lines to detect any issues on either side.

(PGI, Director, gerontopole 2015)

The gerontopoles are faced with a complex challenge: bringing together professionals who differ considerably in terms of competences, activities and even culture into the same shared mission requires demanding levels of collaboration and cooperation.

\section{Gerontopoles: centers of excellence and innovation with boundless research ambition}

The gerontopoles were created following the example of the French cancer-dedicated hubs named canceropoles $^{7}$ and represent new types of research clusters aimed at developing projects in the fields of life expectancy and ageing through encouraging multidisciplinary methods and multi-professional structures. As veritable centers of excellence, they are spaces that invite innovation, acting to stave off elderly dependency and age-related conditions, while recognizing the value of human and social science approaches. The research focuses of the gerontopoles, as defined by the ASV Act, are subjects relating to "normal and pathological ageing" (translation; ASV Act), life expectancy, neuroscience and cognitive function, quality of life and loss of autonomy. Preventing dependency and detecting those most frail nevertheless remain foremost in the gerontopoles' missions (Gonthier, Achour and Geffroy, 2015), with the determination to apply scientific results to public health policy.

Scientific results can have an influence over policies of action for the elderly.

(PGI, Director, gerontopole 2015)

To achieve this, the gerontopoles benefit from collaboration with university hospital physicians and researchers working on ageing, healthcare quality, the consequences of chronic disease and loss of autonomy. 
Our strength is in our consultations for each project: We have groups of experts that equate to steering committees, expert committees.

(Director of the Bourgogne gerontopole in Franche Comté)

Like every gerontopole, we are a center of scientific expertise, with over 200 regional professionals working here, from local community groups to start-ups, healthcare institutions, and even user representatives. We have two major focuses: training, and research. Yes, it is to support healthy ageing alongside all different professionals, we are not with the elderly in their day-to-day care, our objective is to be innovative and to support innovation across the region.

(Pays de la Loire gerontopole, CEO, gerontopole 2010)

We have also set up a scientific council chaired by one of the creative minds behind the gerontology services of Rouen university hospitals in order to encourage scientific expertise.

(Seine Estuaire Normandie gerontopole, President, gerontopole 2017)

They include think tanks (scientific council, expert committee) that analyze the appropriateness of projects in terms of ethics, pedagogy and science, working independently with realistic evaluation. Each gerontopole is, therefore, by definition, a research entity.

\section{Applied research and support for social and technological innovation}

Applied research and advances in home automation are more and more sought after in the management and support of frail elderly individuals. Yet, these innovative tools need to be truly assimilated by the elderly themselves in order for them to become part of their everyday lives. It is essential to build awareness among the general public and professionals about the different technical aids that are available, ensuring they fulfill the needs assessed before their implementation. The gerontopoles thus organize this essential collaborative process between physicians and industry workers. They provide support and information on the users' needs to the industry professionals who call upon their advice, while offering areas for experimentation where they can develop new products and concepts. The AURA gerontopole, for example, publishes calls for experiments with the aim of supporting leaders of innovative regional projects.

Four projects are being supported by the AURA gerontopole in 2019: evaluation of the healthy-ageing commissions organized by the local Saint Etienne association (OSPA) and support for two experiments on inciting regular, adapted physical activity in nursing homes, as well as projects conducted in the city's public areas involving innovative tailor-made solutions and our support of a stroke-prevention program in pharmacies using electronic boxes to record risk factors.

(Project leader, Auvergne Rhône-Alpes gerontopole)

In these cases, the innovations that receive support are often technical, although they can be social and organizational. Still, in the current climate where residences are being requisitioned to avoid hospitalizations, to respond as best as possible to shortages in institutions, as well as to the desires of the elderly themselves, technological innovations can offer more comfort and safety, along with leisure activities and distractions, not to mention the 
possibility of keeping in contact with family and friends. This kind of set up evokes ideas of a healthcare ecosystem for the home, encouraging research into global approaches centered on the individual and care pathways that are less confusing and traumatizing. Digital and automated home solutions in this context represent tools capable of rethinking the entire hospital-centered organization we have today, getting rid of barriers between healthcare and medico-social fields, between city GPs or other local centers and hospitals. On the other hand, at-home treatment and management often necessitates technical devices that must also insure increased safety. The most commonly used are those for detecting falls and geolocation technology, although many more solutions are being developed every day, such as the smart walking cane, walking sensors, smart watches/bracelets and so on. Supervising and regulating use of these technical devices and innovations offered to subjects is essential to guarantee the tools provide the appropriate solutions, and are adapted to needs. The gerontopoles, in addition to their functional link with industry, support and advise businesses in order to help them better understand and empathize with the expectations and needs of the elderly, while also creating new tools adapted to their needs. The gerontopoles thus have a responsibility and mission to encourage innovation, experimenting in real-life contexts then distributing and highlighting the value of these innovations across their entire region. This is why the Gérond'if gerontopole (Ile de France) qualifies its studies in the field of innovation as "gerontotechnologie". With the advantage of their great experiments and research into the conditions of old age (particularly regarding Alzheimer's disease), Gérond'if promotes research, innovation and evaluation in the fields of geriatric medicine and gerontology.

Another group that previously defined its role as to highlight the value of research to industry and since then has transformed into silver economy technology and innovation, it's all gerontotechnology.

(Gérond'if Ile de France gerontopole, Director, gerontopole 2014)

Our vision is to galvanize action on ageing among all those working in research, healthcare, training, and business.... We conduct evaluations of projects and studies, measuring the innovation's acceptability and influence on quality of life for the elderly, carers, and the professionals surrounding them.

(Senior Executive Vice-President of Gérond'if)

\section{Real-life experiments: the methodology of a living laboratory}

The relevance of finding a balance between technological innovation and the human factor involves looking closely at how solutions are applied. These studies on device use are opportunities for the gerontopoles, enabling them to insist on the need to include the elderly subjects, their carers and their nurses in both the development and evaluation of the innovations offered to them so as to insure they fulfill their needs. The recent report by Dominique Libault (2019) on the conference on old age and autonomy (Grand âge et Autonomie), delivered to the Health Ministry on 28 March 2019, confirms this trend. It validates using preventative healthcare approaches, which aim to work so that signs of frailty in elderly subjects must be detected very early so as to reduce the risk of loss of autonomy. While these matters have in the past not been prioritized by public health policies, change appears to be afoot. The report goes on to state that France is in the midst of a changing environment that must not be ignored and should be thought about in a careful and precise way so 
that innovations are accepted by those who will use them. Based on surveys among inhabitants, the Libault report underlines the key role of users as participants in their own healthcare pathway, which enables the real needs of citizens to be identified. For this, the AURA gerontopole adopts a living laboratory methodology centered on autonomy and healthy ageing "Autonomie et Bien vieillir", 8 aimed at creating new economic solutions to support innovations that fulfill the needs of the elderly. The elderly are thus at the heart of innovation:

We conduct many qualitative studies on technology use among users and residents, feasibility studies, real-life experimentations, and focus groups, too, to place innovation at the heart of a collective process involving all professionals of this field: engineers, but also the patients themselves, of course, sometimes friend and family carers, and professional carers too.

(Project leader, AURA gerontopole)

Other gerontopoles create teams of users (elderly, family or friend carers, and professional carers) to work within the actual expert committees of the gerontopoles with the aim of getting their participation in the design and evaluation of new products and services.

We have created specific teams of elderly subjects to work on the issue.... They are present (as user representatives) in governance meetings, decisive committees, and strategic committees that assemble users and financers of the entire cluster... In addition, they are present in the committees, in the expert groups for projects, without exception of course, as well as in the research programs.

(Koz'ensemble Manager, gerontopole 2015)

It is the heart and soul, so much so that, in fact in September you'll see it in our marketing, we have launched a club for local users, they will meet regularly to discuss essential issues, it was their own idea to meet in order to be more effective and really work together. Supporting and debating on innovations of the future and the issues they are facing right now.

(Pays de la Loire gerontopole, CEO, gerontopole 2010)

\section{The gerontopoles: centers for teaching and training}

In the form of scientific conferences and seminars, talks for the general public or even regional themed days for professional carers, patients and their families, researchers, professionals of the social sector, students, journalists, business leaders or politicians, the gerontopoles offer local educational opportunities of all shapes and sizes, accessible to everyone in their local area. The majority of these events are spread out to reach people locally as much as possible in order to spread good practices and promote good treatment. Often interactive, these educational programs usually cover multiple disciplines. Sometimes, an academic university course is linked with themed days or organized seminars. One of the priorities is to offer better training and support for family and friend carers, as they play a key role in how many age-related conditions are managed and coped with (Alzheimer's, Parkinson's, cancer ...). Realizing this, the pays de la Loire gerontopole has created a "carer school", while the Normandy organization puts on a cycle of conferences 
all year round. The Bourgogne Franche-Comté gerontopole has designed a multidisciplinary follow-up of a cohort of unofficial carers with the aim of better identifying the needs and expectations of those caring for patients suffering from chronic disease.

We take a real stance of engineering in training, or you could say of engineering design, it's training courses that don't yet exist, to respond to the needs of our members.

(Director of Bourgogne Franche Comté gerontopole)

\begin{abstract}
Yes, there's lots of work to do, they [the at-home carers] are on the front lines of healthy ageing, yet when you look at what is provided for them, the training and services, it's not much, it's incredible. There's lots of progress to be made in training courses. We can bit by bit improve their practices, make them more professional, help them, offer them more security in their jobs, teach them to detect problems, anticipate problems. There is real work to do. All that means we must try to improve this training, and this is the kind of work that can be carried out by the gerontopoles.
\end{abstract}

(AURA gerontopole, Medical Vice-President, gerontopole 2015)

\title{
The gerontopoles: local specificities guaranteeing approaches adapted to the elderly
}

The gerontopoles have some points in common (research, innovation, training, professional collaboration), yet each region has its own particularities, resulting from the local background of each gerontology institution and the research focuses chosen by the different professionals working on ageing. In the beginning, our gerontopoles were made up of regional initiatives carrying out activities with the potential to contribute to clinical research and innovation. In Toulouse, for example, significant research was conducted into Alzheimer's disease and malnutrition; in the pays de la Loire region, research was focused on adapting local organization and services to ageing; in Bourgogne, it was on fall prevention and ethics; in Auvergne-Rhône-Alpes on the field of first aid (via GPs as well as paramedics and family and friend carers of the elderly) and human and social sciences through the study of patient pathways and real-life experiments. As centers for learning and training on professions linked to life expectancy, as well as being hubs of research and specialist expertise, not to mention spaces for exchange of knowledge and excellence, the gerontopoles are at times similar to permanent exhibition centers.

Beyond the research focuses and training courses, the associative organizations themselves even vary from one gerontopole to another, from the social and cultural environment, the establishment's size and number of employees (from all voluntary to 67 employees), to the financing source (ARS, INSERM, private health insurance ...) and different local partners (see Appendix 2).

We have annual subscriptions with high fees of 80 euros for associations to 500 euros for large groups, though as a result there are not many ... the committee members are legal entities, which means that these are real authoritative bodies that have a role to play, in governance, mediation, and decision-making, but ... on the other hand do not even have any creative potential, as for this we have representatives from specific deliberating bodies. 


\section{N. Barth et al.}

The idea is to have each of the 7 founding members taking turns to preside. We currently have 70 subscribing members, including institutions, public and private businesses, healthcare professionals, health services, and of course those affected by the issue of ageing - it's no small number. At our gerontopole, we have also kept the structure very small in terms of staff, for example at the moment there is one person who is director, secretary, and project manager. She does it all! We have an executive committee where all the agents take an active role.

(Seine Estuaire Normandie gerontopole, President, gerontopole 2017)

The influence of the ARS, regional councils, health insurance companies and universities on each gerontopole varies widely, and can hamper operations. In Bourgogne FrancheComté, for example, the gerontopole has to coordinate with two different administrative regions with contrasting backgrounds and local conditions.

This is also what makes us so strong: we are all ready to collaborate in koz'ensemble we don't have any paid employees and it is precisely this role we are lacking.

(Koz’ensemble Manager, gerontopole 2015)

The gerontopoles built themselves progressively, developing collaborations within their regions, and doing so without extensive finance from the state, unlike the canceropoles and AIDS centers. While there are disparities, reports evoke the possible collaborations that could emerge among different French gerontopoles:

What you need to understand is that each locality has its particularities, all those working in French gerontopoles are focused on the same dominant issue: the impact of ageing on the future of our society, the risk of frailty associated with ageing, and how to prevent it in order to enable the elderly to have better quality of life. There are thus different approaches, yet which are highly complementary, hence the great interest in coming together in the future.

(Novella, Hospimédia, 2014)

\section{Conclusion}

Geriatric medicine is a scientific field that spreads beyond the hospital and health sector in order to support healthy and high-quality ageing and prevent dependence. The clusters of gerontology, a.k.a. the gerontopoles, work to deal with the new demand of elderly people living at home, which is growing in terms of quality and quantity. The goals are to improve support for the elderly through more effective research that involves multiple fields in collaboration and can be directly applied in order to improve quality of life at home or in nursing homes. Unifying competences and projects, mobilizing and bringing together all professionals working in gerontology, creating a closely knit network involving both state and private players, both to their advantage and that of the patients - these are the main priorities of the gerontopoles.

The gerontopoles stimulate clinical practices and research. They provide their expertise to centers of learning, leading to better-adapted and appropriate practices being passed along in the medico-social fields as well as to the general public. They also offer industry results that validate and add value to their products, proving their reliability and acceptability. A great majority of the French elderly prefer to be able to remain at home in 
their old age. As a result, more and more innovations are required to improve individual services, encouraging and enabling social links to be maintained in safety, using many technological advances. The gerontopoles thus enable the elderly to live at home while still having access to diagnostic tools, innovations and treatment research.

The creation of gerontopoles has also created a hub of exchange, deliberation, advice and action, involving greater numbers of decision-makers, all within reasonable budgets in order that the old-age stage of life benefits social progress and techniques. This coconstruction model is founded on the participation of researchers, professionals working in healthcare and local policy makers (community organizations and industry), enabling partners from widely different cultures and backgrounds to be engaged and mobilized, creating a region-wide network united for prevention of dependence and the study of ageing.

The gerontopoles similarly improve how we approach and think about organizing our local healthcare structures and create coherent training across the region. There are particularities to each locality and differences in organizations depending on location and environmental context (local-specific issues, cultural anchoring, local economics ...). We see this diversity as an asset to the gerontopoles, as they work in harmony with all implicated local professionals, relying on the local competences and expertise and responding to the needs and desires of the elderly in consideration of their surroundings and lifestyle.

\section{Notes}

1 In 2060 one-third of the French population will be over 60 years (Libault, 2019). In 2030, one out of two will be over 50 years (De Lapasse, 2018). Yet, it is the growth in people aged over 75 years that is the most significant: their numbers will triple, while that of people over 85 years will quadruple by 2040 (De Lapasse, 2018).

2 Ninety percent of the French population prefer remaining at home (summary of the state report of the French Court of Audit; Chambre Régionale et Territoriale des comptes, cours des comptes 2016).

3 The term "gerontopole" was employed for the first time in 2005 by Professor Pierre Pfitzenmeyer (Dijon university hospitals) to mobilize and bring together the driving forces of research and development to focus on new practices, services and products (Gonthier, Achour and Geffroy, 2015).

4 The French gerontopoles were only recently created, the first appearing in Toulouse in 2007. Since then, these hubs have progressively spread throughout France: the Bourgogne Franche Comté pole of gerontology and innovation and the Pays de la Loire gerontopole (2010), the AURA gerontopole (2014), Koz'ensemble and the Champagne-Ardennes gerontopole (2015), Gérondif (2016), the Normandy gerontopole (2016) and the Sud gerontopole (2019).

$5 \mathrm{We}$ were able to ask representatives of the following gerontopoles: Pôle Gérontologique et d'Innovation de Bourgogne Franche-Comté, Gérond'if, Gérontopôle de Normandie, Koz'ensemble, Gérontopôle Pays de la Loire and Gérontopôle AURA (Appendix 1).

6 The interviews were conducted with representatives of two gerontology centers, of Forez and vallée du Gier, the Office Villeurbannaise des Personnes Agées et des Retraités (OVPAR), Isère Gérontologie and a representative of the Autonomy committee of the ARS.

7 Galvanized by the French cancer plan of 2003-2007, the cancer-specific hubs (canceropoles) were created to improve the quality of management of patients, develop shared solutions, and support research, promoting the transfer of academic findings into clinical and industrial applications. The canceropoles insure the promotion of scientific excellence, highlight the value of interdisciplinary collaboration and remove obstacles between researchers, physicians and industry.

8 So-called living laboratories promote innovative practices, providing real fields of experimentation, access to cohorts (with support from the university hospitals), methods and tools, mobilizing multidisciplinary approaches in the fields of autonomy and healthy ageing (anthropology, economy, ethics, geriatrics, general medicine, sociology, urbanism, etc.). The elderly are themselves participants, contributing to the construction of their own lifestyle and conditions. 


\section{N. Barth et al.}

\section{References}

ASV Act (2015). Annexe de la Loi n ${ }^{\circ} 2015-1776$ du 28 décembre 2015 relative à l'adaptation de la société au vieillissement, 2015.

Chambre Régionale et Territoriale des comptes, cours des comptes (2016). Le maintien à domicile des personnes âgées en perte d'autonomie. Synthèse du rapport publique thématique de la cours des comptes, July, 5-18.

Champio, J., Colin, C., Lesdos, C. and Quénechdu, V. (2018). Bilan démographique 2017. Insee, No. 1683, January.

De Lapasse, B. (2018). Le vieillissement de la population et ses enjeux. Fiche d'analyse de l'Observatoire des territoires 2017, January.

Fondation de France (2016). Les solitudes en France. Available at: www.fondationdefrance.org/sites/ default/files/atoms/files/les_solitudes_en_france_2016_-_synthese.pdf [Accessed 24 March 2010].

Gonthier, R., Achour, E. and Geffroy, L. (2015). Gérontopole: hier, aujourd'hui et demain. Revue Hospitalière de France, January/February, 67-77.

Grand, A. (2016). Du rapport Laroque à la loi relative à l'adaptation de la société au vieillissement: cinquante-cinq ans de politique vieillesse en France. Revue Vie Sociale, 13-25.

INSEE (2019). Tableaux de l'économie française: espérance de vie et mortalité. 26 March. Available at: www.insee.fr/fr/statistiques/3676610?sommaire=3696937 [Accessed 9 August 2010].

Libault, D. (2019). Rapport de la concertation, Grand âge et autonomie. Rapport Ministère des solidarités et de la santé, 228.

Novella, J.-C. (2014). La mutualisation des Gérontopôle rendra plus lisible la force organisée autour du vieillissement. Hospidémia, April. 